\title{
AN ORTHOTROPIC MACROMECHANICAL MODEL WITH DAMAGE FOR THE ANALYSIS OF MASONRY STRUCTURES
}

\author{
C. Gatta and D. Addessi \\ Department of Structural and Geotechnical Engineering, Sapienza University of Rome \\ Via Eudossiana, 18, 00184, Rome, Italy \\ e-mail: \{cristina.gatta,daniela.addessi\}@uniroma1.it
}

Keywords: Masonry, Macromechanical approach, Orthotropic response, Damage, Nonlinear analysis.

\begin{abstract}
The in-plane response of masonry walls is analyzed by using a novel macromechanical damage model. This is able to capture the directional mechanical properties characterizing regular masonry textures by adopting an orthotropic description of the elastic and inelastic behavior. A damage matrix, defined in terms of damage independent scalar variables, is introduced in the constitutive law to describe and distinguish the stiffness degradation due to tensile, compressive and shear states along masonry natural axes, fixed as the parallel and normal direction to bed joints. The model is implemented in a finite element procedure, where the mesh-dependency drawback is overcome by adopting a classical nonlocal integral approach.

Comparisons of numerical and experimental results are performed to test the model capability of describing influence of the orientation of applied stresses with respect to bed joints direction. Moreover, a numerical study is conducted with reference to different masonry textures with the aim of evaluating the effect of bricks and mortar relative arrangement on the elastic properties of the homogenized material. Finally, the response of a large scale masonry wall subjected to seismic loads is studied and the obtained pushover curve is compared with those collected from existing literature models .
\end{abstract}




\section{INTRODUCTION}

Masonry is a composite material, made of units, bricks or blocks, properly connected with or without mortar. Its heterogeneous nature leads to mechanical behavior characterized by complex stress distributions in the constituent materials, with nonlinear, non-symmetric and usually anisotropic macroscopic response. To numerically reproduce these peculiar features several modeling strategies [1] have been developed, ranging from simplified to very sophisticated models. Within the Finite Element (FE) framework, multiscale [2, 3, 4] and micromechanical [5, 6] approaches provide accurate predictions of the structural response, as these naturally account for geometry, arrangement and constitutive behavior of masonry constituents. Enhanced formulations were also proposed based on multidomain models [7, 8]. The main drawback of such modeling techniques consists in the high computational burden required and, consequently, their applicability is limited to the analysis of small elements or structural details.

To date, macromechanical models, which consider masonry as an equivalent homogeneous medium where the constituent materials are no longer distinguishable, represent the best compromise between accuracy and computational cost. These models establish proper relationships between average masonry strains and stresses, commonly making use of constitutive laws with damage and plasticity inner variables. Despite isotropic models are largely adopted [9, 10, 11], because of their simplicity and reduced number of material parameters needed, these do not allow to describe the anisotropic nature of the response, typical of masonry with regular texture in which mortar joints act as plane of weakness. Thus, the most advanced macromodels account for the substantial discrepancy among mechanical properties observed in different material directions by making use of anisotropic plasticity or damage formulations [12, 13, 14].

It should be remarked that the anisotropic behavior usually reduces to an orthotropic one, as shown by the experimental correlation [15] between the ratios Young's modulus-to-Poisson coefficient defined along the masonry natural/material axes, fixed as the normal and parallel direction to bed joints orientation. In heterogeneous materials, onset and evolution of nonlinear phenomena can modify the initial orthotropic response, leading to a more general anisotropic behavior. However, for masonry it is reasonable to assume that damage development does not alter the initial material symmetries [13], as microcracks are usually located at brick-mortar interface and follow the directions of material axes. Hence, failure criteria for masonry can not be expressed only in terms of principal stresses or strains, as usually adopted for isotropic materials, but have to take into account influence of orientation of applied stresses with respect to bed joints direction. As suggested in [16], two alternative representations are possible: the criterion can be expressed either in terms of principal stresses and their orientation with respect to bed joints or in terms of stresses referred to the natural axes, being this latter representation more suitable for finite element modeling.

Basing on the previous considerations, this paper presents an orthotropic macromechanical model with damage tailored to the $2 D$ analysis of masonry structures, able to distinguish stiffness and strength mechanical properties along the material axes. Failure mechanisms due to crushing, cracking and shear are captured by properly defining a damage matrix, considering independent damage variables. Model performance is evaluated through numerical and experimental comparisons and, then, the effect of adopted masonry texture on the level of orthotropy of the elastic response is evaluated. Finally, the pushover analysis of a masonry wall is performed and the effect of damaging mechanisms on the structural response is investigated. 


\section{ORTHOTROPIC MACROMECHANICAL DAMAGE MODEL}

The real heterogeneous masonry material is modeled as a fictitious $2 D$ homogenized orthotropic medium with the natural axes $(T, N)$ as axes of orthotropy. First, the constitutive law is defined in the material axes system $(T, N)$, then, is expressed in the global $(x, y)$ coordinate (see Figure 1) by using standard transformation rules.
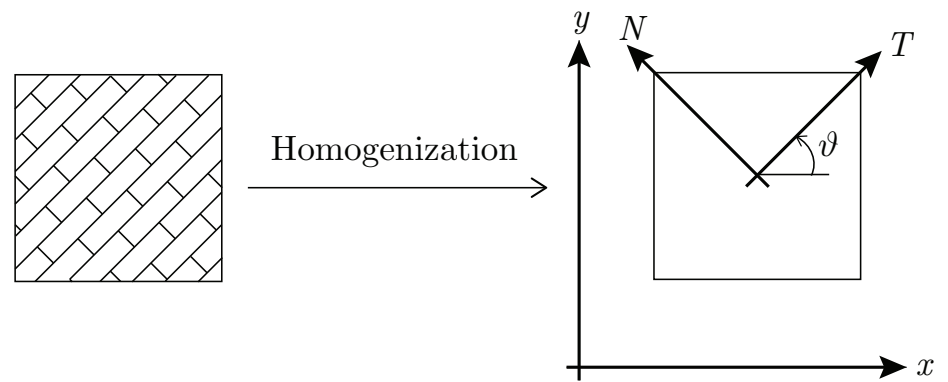

Figure 1: Global $(x, y)$ and material $(T, N)$ axes of the homogenized masonry material.

The stress-strain relationship, derived on the basis of the damage mechanics energy equivalence principle, results as:

$$
\boldsymbol{\sigma}_{T N}=(\mathbf{I}-\mathbf{D})^{T} \mathbf{C}_{T N}(\mathbf{I}-\mathbf{D}) \boldsymbol{\varepsilon}_{T N}
$$

In Eq. 1. $\mathbf{C}_{T N}$ is the elastic orthotropic constitutive matrix of the undamaged material for plane stress conditions, $\mathbf{I}$ is the $3 \times 3$ identity matrix and $\mathbf{D}$ the damage matrix containing the three scalar variables $D_{T}, D_{N}$ and $D_{T N}$, as follows:

$$
\mathbf{D}=\left[\begin{array}{ccc}
D_{T} & 0 & 0 \\
0 & D_{N} & 0 \\
0 & 0 & D_{T N}
\end{array}\right]
$$

To account for the unilateral effect typical of masonry material, the introduced damage variables $D_{T}$ and $D_{N}$ are defined as a proper combination of damage parameters for tensile, $D_{i t}$, and compressive, $D_{i c}(i=T, N)$, strain states, as follows:

$$
\begin{aligned}
& D_{T}=\alpha_{T} D_{T t}+\left(1-\alpha_{T}\right) D_{T c} \\
& D_{N}=\alpha_{N} D_{N t}+\left(1-\alpha_{N}\right) D_{N c}
\end{aligned}
$$

The weighting coefficients, $\alpha_{T}$ and $\alpha_{N}$, are introduced to rule the stiffness recovery related to the re-closure of tensile cracks when the material undergoes compressive states.

All the damage variables, $D_{i t}, D_{i c}$ and $D_{T N}$, can range between 0 , corresponding to the undamaged material, and 1 , representing the completely degraded state. Furthermore, these have to satisfy the irreversible thermodynamic condition such that $\dot{D}_{i t} \geq 0, \dot{D}_{i c} \geq 0$ and $\dot{D}_{T N} \geq 0$ and the constraints $D_{i t} \geq D_{i c}$. Each damage variable is associated to a peculiar failure mode, as sketched in Figure 2, thus distinguishing degrading mechanisms due to tensile and compressive states, parallel and normal to bed joints, and shear states. Accordingly, to drive the evolution of damage, associated variables are defined on the basis of the strain state acting in the material axes system. These result as:

$$
\begin{aligned}
& Y_{T}=\varepsilon_{T}+\tilde{\nu}_{N T} \varepsilon_{N} \\
& Y_{N}=\varepsilon_{N}+\tilde{\nu}_{T N} \varepsilon_{T} \\
& Y_{T N}=\gamma_{T N}
\end{aligned}
$$


where $\tilde{\nu}_{N T}=\left[\left(1-D_{N}\right) /\left(1-D_{T}\right)\right] \nu_{N T}$ and $\tilde{\nu}_{T N}=\left[\left(1-D_{T}\right) /\left(1-D_{N}\right)\right] \nu_{T N}$ are the degraded Poisson ratios under uni-axial stress state.

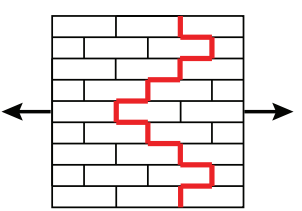

(a)

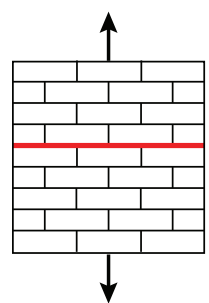

(b)

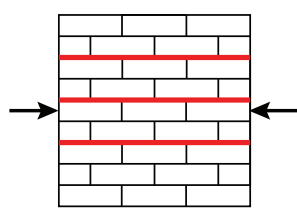

(c)

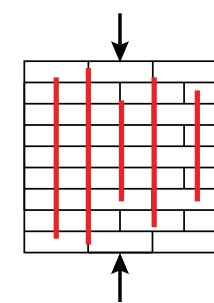

(d)

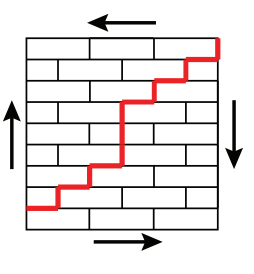

(e)

Figure 2: Failure modes associated to (a) $D_{T t}$, (b) $D_{N t}$, (c) $D_{T c}$, (d) $D_{N c}$ and (e) $D_{T N}$.

Furthermore, a proper limit surface is introduced to rule damage activation, being geometrically defined as the intersection of an ellipsoid and an elliptic cone in the space of the damage associated variables. Only few material parameters are needed to construct the surface, that is the uni-axial damage thresholds in the parallel, $Y_{T t 0}$ and $Y_{T c 0}$, and normal, $Y_{N t 0}$ and $Y_{N c 0}$, direction to the bed joints orientation (by distinguishing them to account for the non-symmetric behavior in tension and compression, as the subscripts ' $t$ ' and ' $c$ ' indicate), the pure shear $Y_{s 0}$ threshold and bi-axial compressive $Y_{c c 0}$ threshold (see Figure 3 ).

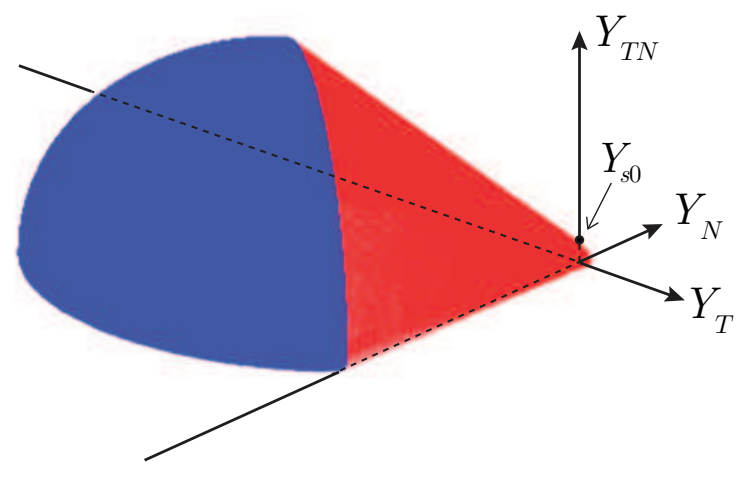

(a)

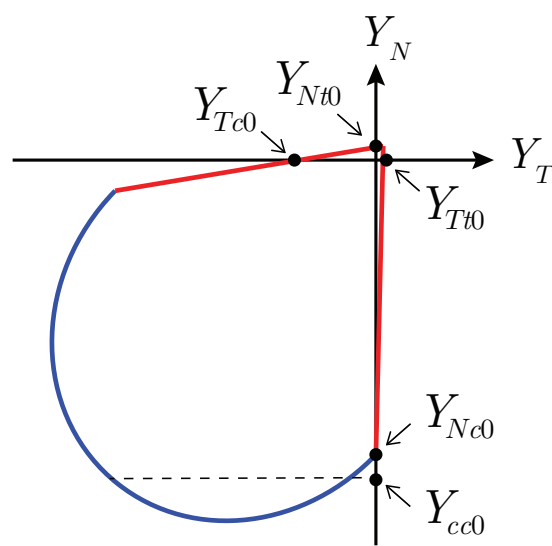

(b)

Figure 3: Damage limit surface in the (a) $Y_{T N}$-positive damage associated variables space and (b) $Y_{T}-Y_{N}$ plane.

According to the damaging criterion, points lying inside the surface represent material elastic states, otherwise damage evolution occurs and the damage thresholds $Y_{T 0}, Y_{N 0}, Y_{T N 0}$ have to be identified. Once evaluated the activation thresholds, the following rational evolution rules are assumed:

$$
D_{i t}=\frac{Y_{i}-Y_{i 0}}{a_{t} Y_{i}+b_{t}} \quad\left(Y_{i} \geq 0\right), \quad D_{i c}=\frac{\left|Y_{i}\right|-\left|Y_{i 0}\right|}{a_{c}\left|Y_{i}\right|+b_{c}} \quad\left(Y_{i}<0\right), \quad D_{T N}=\frac{\left|Y_{T N}\right|-\left|Y_{T N 0}\right|}{a_{s}\left|Y_{T N}\right|+\bar{b}_{s}}
$$


with $i=T, N$ and $a_{t}, a_{c}, a_{s}, b_{t}, b_{c}, \bar{b}_{s}$ material parameters selected on the basis of uni-axial tension, compression and pure shear tests. Peak strengths of stress-strain relationships are mainly governed by $b_{t}, b_{c}$ and $\bar{b}_{s}$ parameters, while $a_{t}, a_{c}$ and $a_{s}$ influence the slope of softening branches. It should be underlined that a linear variation of $\bar{b}_{s}$ with the compressive stress $\sigma_{N}^{c}\left(\bar{b}_{s}=b_{s}+\left|\sigma_{N}^{c}\right| b_{s}\right)$ is introduced to phenomenologically capture the well-known increment of the fracture energy associated to MODE II of failure with the normal compressive stress. As emerges from Eq. 5, the sign of $Y_{T}$ and $Y_{N}$ variables permits to distinguish between damage in tension and compression along each material axis.

The presented model is introduced in a 4-node isoparametric FE and implemented in the FEAP code [17]. A classical nonlocal integral procedure [18] is adopted to overcome the meshdependency drawback emerging in case of strain-softening behavior. Thus, the local damage associated variables in Eq. 4 are replaced by their integral definition, depending on the nonlocal radius $l_{c}$.

\section{BI-AXIAL FAILURE DOMAINS}

To validate the proposed model and show its capability of describing influence of the applied stresses with respect to bed joint direction, the experimental tests performed by Page [19, 20] are numerically reproduced. Test conditions were designed to impose bi-axial stresses, oriented at various angles $\vartheta$ with respect to the bed joints, on square panels made of half-scale solid clay units arranged in running bond texture. Failure surfaces were obtained in terms of principal applied stresses and their orientation with respect to the material axes.

Table 1 contains the material parameters used to perform the numerical analyses, which are selected according to data provided by Page et al. [19, 20, 21].

Elastic parameters

\begin{tabular}{cccc}
\hline$E_{T}[\mathrm{MPa}]$ & $E_{N}[\mathrm{MPa}]$ & $\nu_{T N}$ & $G_{T N}[\mathrm{MPa}]$ \\
\hline 5700 & 5600 & 0.19 & 2350 \\
\hline
\end{tabular}

Damage thresholds

\begin{tabular}{cccccc}
\hline$Y_{T t 0}$ & $Y_{T c 0}$ & $Y_{N t 0}$ & $Y_{N c 0}$ & $Y_{s 0}$ & $Y_{c c 0}$ \\
\hline $6.8 \mathrm{E}-05$ & $6.8 \mathrm{E}-04$ & $4.2 \mathrm{E}-05$ & $1.2 \mathrm{E}-03$ & $1.3 \mathrm{E}-04$ & $1.1 Y_{N c 0}$ \\
\hline
\end{tabular}

Table 1: Material parameters for Page panels.

A good agreement emerges between numerical and experimental outcomes, as Figure 4 shows by comparing the experimental (dots) and numerical (solid lines) failure domains for different values of $\vartheta$ angle. To be noted is that, in case of $\vartheta=0^{\circ}$, non-symmetric shape of the failure surface, with respect to the bisecting axis, is found. This is due to the different mechanical properties defined along material axes $T-N$, which correspond to the principal stress directions. By varying $\vartheta$, the asymmetric characteristic of the failure surface is gradually lost until the symmetric shape is fully resorted at $\vartheta=45^{\circ}$ (see Figure 4(c)), as a consequence of the stress acting along the material axes. 


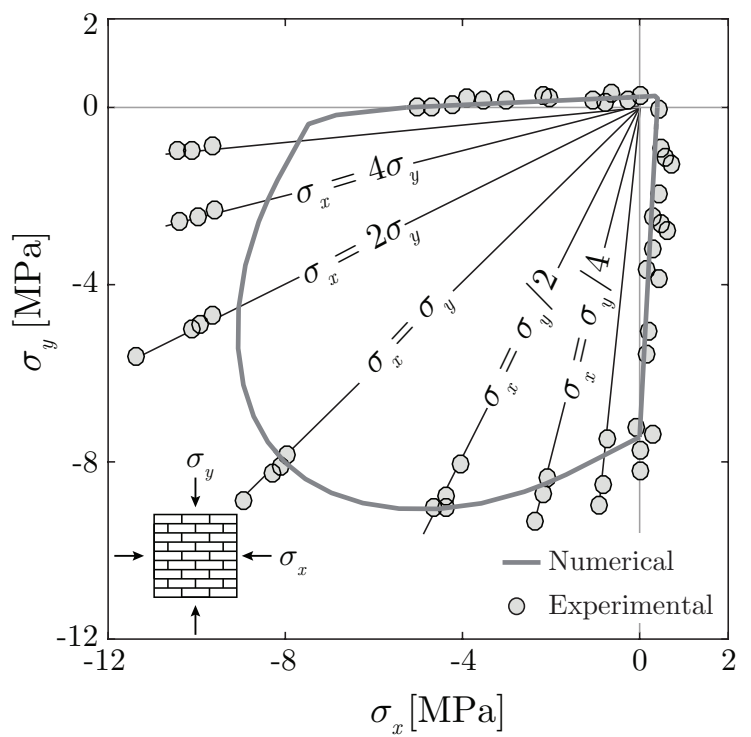

(a)

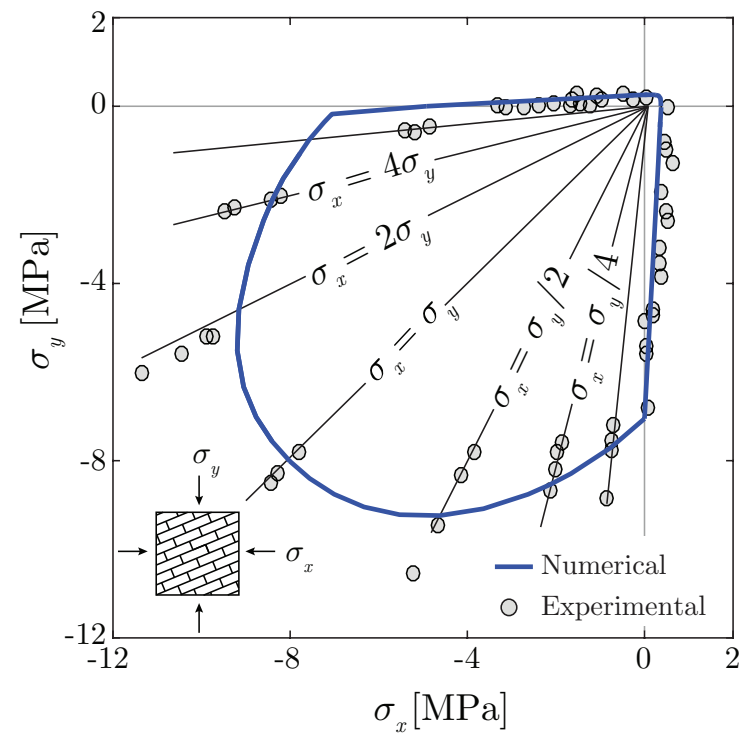

(b)

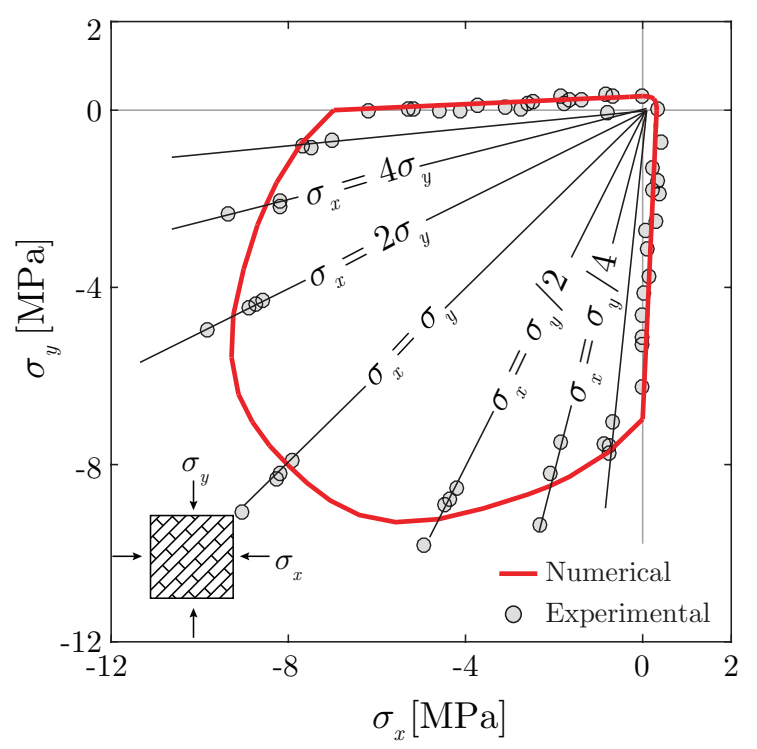

(c)

Figure 4: Failure surface for (a) $\vartheta=0^{\circ}$, (b) $\vartheta=22.5^{\circ}$ and (c) $\vartheta=45^{\circ}$ : comparison between numerical (solid line) and experimental (dots) results from Page [19, 20].

\section{EFFECT OF TEXTURE}

As known, the level of orthotropy of the homogenized material response depends on geometry, size, mechanical properties and arrangement of the constituent materials. Hence, to investigate the effect of bricks and mortar relative arrangement on the elastic properties of the homogenized material, different masonry textures are here analyzed.

Figures 5(a-d) show examples of masonry-like composite textures with rectangular bricks, namely running, English, Flemish and header bond. Brick dimensions are $250 \times 120 \times 60 \mathrm{~mm}^{3}$, whereas $10 \mathrm{~mm}$ thick mortar is considered.

To evaluate the effective elastic properties, a homogenization procedure [22] is adopted, based on the selection of a cell representative of the periodic masonry (RVE), which generates the 
regular arrangement by repeating itself in the real medium. The selected cells for each texture are highlighted in Figure 5 with white blue windows.

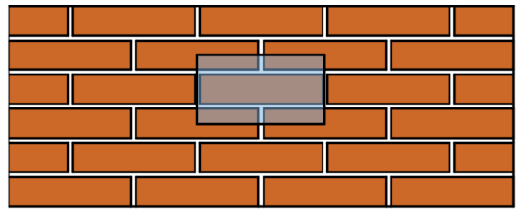

(a)

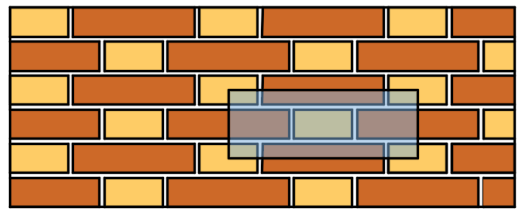

(c)

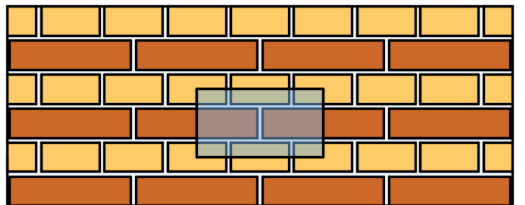

(b)

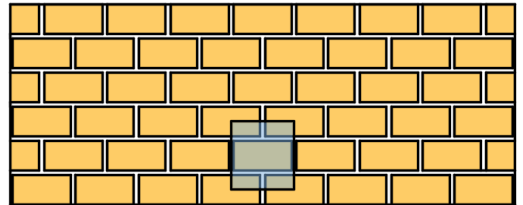

(d)

Figure 5: Masonry textures: (a) running, (b) English, (c) Flemish and (d) header bond.

Each RVE is modeled at the microlevel by separately discretizing bricks ' $b$ ' and mortar ' $m$ ' by 4-node quadrilateral FEs. Linear elastic isotropic constitutive laws are adopted for both with Young's moduli $E_{b}=10000 \mathrm{MPa}$ and $E_{m}=1000 \mathrm{MPa}$, and Poisson ratios $\nu_{b}=\nu_{m}=0.15$. Then, the macroscopic strain vectors [ $\left[\begin{array}{lll}1 & 0 & 0\end{array}\right],\left[\begin{array}{lll}0 & 1 & 0\end{array}\right]$ and $\left[\begin{array}{lll}0 & 0 & 1\end{array}\right]$ are sequentially imposed to the RVE as input kinematic conditions. On the basis of these, the microscopic displacement field at each point of the RVE is expressed as the superposition of two different parts, as follows:

$$
\mathbf{u}=\overline{\mathbf{u}}+\tilde{\mathbf{u}}
$$

where $\overline{\mathbf{u}}$ is the assigned displacement, depending on the kinematic map linking the macro and micro level, and $\tilde{\mathbf{u}}$ is the fluctuation field satisfying the periodicity conditions on the RVE boundary. The microscopic strain field is then derived by applying the compatibility conditions and the stresses are computed on the basis of the constitutive response of each constituents. Then, by applying the Hill-Mandel equivalence principle, the macroscopic stresses associated to the assigned macroscopic strains, and representing the columns of the homogenized elastic matrix $\mathbf{C}_{T N}$, are obtained as shown in Table 2. Here, it can be noted that different levels of orthotropy emerge depending on the adopted masonry texture, with the more significant anisotropic response obtained for the running bond arrangement.

\begin{tabular}{ccccc}
\hline Moduli [MPa] & $\mathbf{C}_{T N}(1,1)$ & $\mathbf{C}_{T N}(1,2)=\mathbf{C}_{T N}(2,1)$ & $\mathbf{C}_{T N}(2,2)$ & $\mathbf{C}_{T N}(3,3)$ \\
\hline Running bond & 6988.3 & 584.7 & 4367.1 & 1745.7 \\
English bond & 6260.4 & 551.9 & 4313.3 & 1681.9 \\
Flemish bond & 6494.6 & 562.3 & 4331.2 & 1701.5 \\
Header bond & 5610.8 & 524.1 & 4259.8 & 1625.9 \\
\hline
\end{tabular}

Table 2: Elastic moduli of the homogenized masonry in Figure 5

To summarize, notwithstanding the initial elastic characteristics can be significantly modified due to onset of nonlinear mechanisms, these can provide useful information to identify cases 
where it is required to resort to anisotropic material description instead of a simplified isotropic one.

\section{PUSHOVER RESPONSE OF A TWO-STORY MASONRY WALL}

To further validate the proposed model, the response to lateral loads of a one-bay unreinforced masonry wall is analyzed and compared with that obtained by existing literature models $[23,24]$. Geometry of the structure (thickness $t=0.6 \mathrm{~m}$ ) and loading conditions are shown in Figure 6(a). The wall is subjected to self-weight $\left(\rho=2 \mathrm{t} / \mathrm{m}^{3}\right)$ and uniformly distributed masses at floor levels, resulting in additional vertical loads about equal to $p_{1}=60 \mathrm{kN} / \mathrm{m}$ and $p_{2}=40 \mathrm{kN} / \mathrm{m}$ at first and second floor, respectively. Then, horizontal forces are applied mimicking a first mode distribution as sketched in Figure 6(a), where $V$ represents the value of the base shear force.

As concerns the mechanical parameters, these are selected according to the data adopted by Salonikios et al. [23]. The authors considered different modeling strategies based on equivalent frame model, macromechanical and discrete element approaches. In the discrete model, bricks and mortar were modeled as elastic material and elastic-plastic interface elements, respectively ( $E_{b}=2400 \mathrm{MPa}$ and $E_{m}=400 \mathrm{MPa}$ ). The assumed tensile and compressive strengths for joints were $f_{t}=0.1 \mathrm{MPa}$ and $f_{c}=3 \mathrm{MPa}$, whereas cohesion was set equal to $0.09 \mathrm{MPa}$. Moreover, to reduce the computational effort, overvalued size of brick was assumed $(0.50 \times 0.25 \mathrm{~m}$ instead of $0.2 \times 0.1 \mathrm{~m}$ ). On the basis of these mechanical and geometrical parameters, the elastic properties of the homogenized masonry are here derived through the procedure described in Section 4 with reference to the RVE depicted in Figure 6(a) and setting $\nu_{m}=\nu_{b}=0.2$. Furthermore, to distinguish between strength properties along masonry natural axes, the representative cell is analyzed at microlevel by using the micromechanical model adopted by Sacco [25], that assumes all the nonlinear mechanisms occurring in mortar joints and accounts for damage and friction phenomena. Setting mechanical properties of constituent materials according to Salonikios et al., the RVE is subjected to macroscopic tensile strain histories parallel and normal to bed joints. The responses plotted in Figure 6(b) in terms of homogenized strain and stress components (red lines) are obtained. On the basis of these, the material parameters to be used in the proposed orthotropic model are derived as contained in Table 3. These correspond to tensile strengths parallel and normal to bed joints equal to $0.15 \mathrm{MPa}$ and $0.1 \mathrm{MPa}$ respectively, according to micromechanical analyses results (see Figure 6(b)). Shear strength is assumed equal to $0.09 \mathrm{MPa}$, whereas compressive strengths parallel and normal to bed joints are $2.5 \mathrm{MPa}$ and $3 \mathrm{MPa}$.

Elastic parameters

\begin{tabular}{|c|c|c|c|c|c|c|}
\hline \multirow{3}{*}{$\begin{array}{c}E_{T}[\mathrm{MPa}] \\
1838.8\end{array}$} & \multirow{3}{*}{$\frac{E_{N}[\mathrm{MPa}]}{1610.4}$} & \multirow{3}{*}{$\begin{array}{l}\nu_{T N} \\
0.18\end{array}$} & \multirow{2}{*}{$G_{T N}[\mathrm{MPa}]$} & \\
\hline & & & & $a_{t / c / s}$ & $b_{t}$ & $b_{c}$ \\
\hline & & & 617.4 & 0.99 & $1.0 \mathrm{E}-05$ & $3.5 \mathrm{E}-03$ \\
\hline & \multicolumn{6}{|c|}{ Damage thresholds } \\
\hline & $Y_{T t 0}$ & $Y_{T c 0}$ & $Y_{N t 0}$ & $Y_{N c 0}$ & $Y_{s 0}$ & $Y_{c c 0}$ \\
\hline & $7.9 \mathrm{E}-05$ & $7.9 \mathrm{E}-04$ & $6.0 \mathrm{E}-05$ & $1.5 \mathrm{E}-03$ & $1.5 \mathrm{E}-04$ & $1.1 Y_{N c 0}$ \\
\hline
\end{tabular}

Table 3: Material parameters for the two-story masonry wall. 


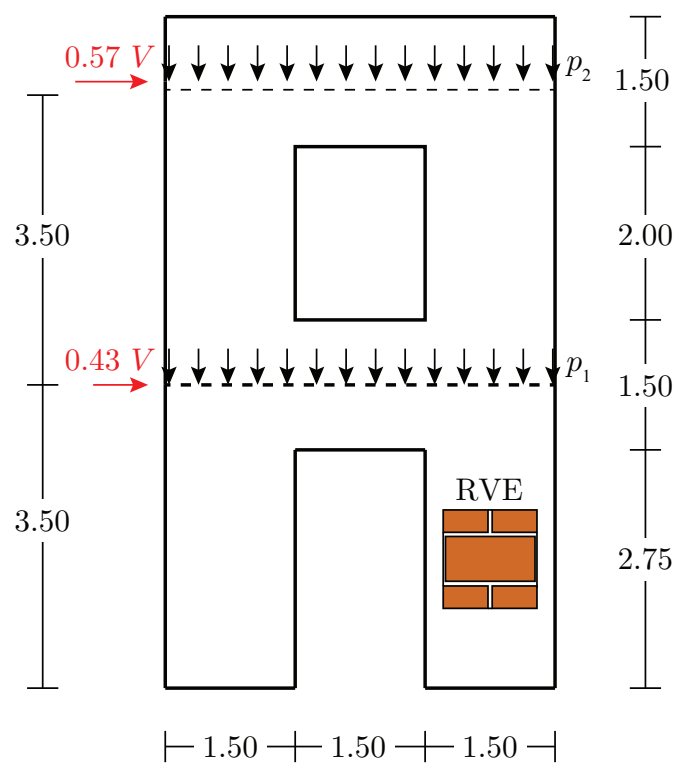

(a)

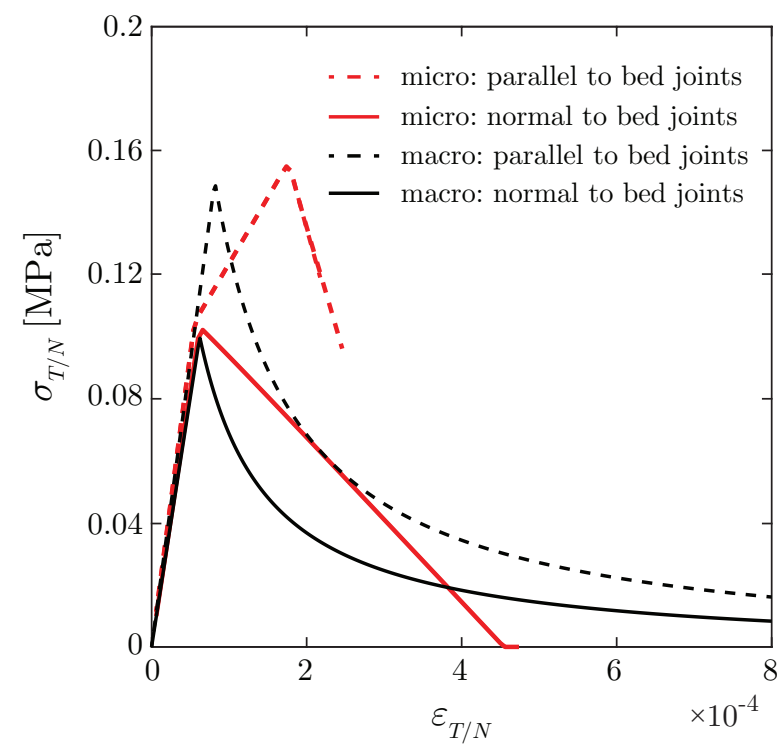

(b)

Figure 6: Two-story wall: (a) geometry (dimension in [m]) and loading conditions, (b) responses to tensile strains parallel and normal to bed joints direction.

A mesh made of 444 4-node FEs is used to perform the numerical simulation, setting the nonlocal radius $l_{c}=350 \mathrm{~mm}$ on the basis of mesh and brick sizes. A two-step analysis is carried out: first the vertical loads are applied, then, the wall is subjected to incremental horizontal forces at floor levels, as shown in Figure 6(a). The structural response, in terms of pushover curve (base shear vs. horizontal displacement of the middle point at the top of the building) is depicted in Figure 7(a) with black line. To be noted is that due to the force-controlled loading, it can not be captured the possible softening branch. The obtained curve correlates well with the results deriving from others studies, as emerges from the comparison provided in Figure 7(a).

As concerns the activated failure modes, Figure $7(b)$ and Figure $8(a, b)$ show the damage maps for $D_{T}, D_{N}$ and $D_{T N}$ at the end of the analysis. These are in agreement with the failure patterns obtained by Salonikios et al. [23] with damage mainly located at the base of the piers of first floor due to the rocking failure mechanisms and in the spandrels at both levels. Damage $D_{T}$ localizes at the corners of the openings, whereas damage $D_{N}$ is located at base of piers of the both levels, where the maximum tensile stresses normal to bed joints occur.

\section{CONCLUSIONS}

- An orthotropic macromechanical model with damage has been proposed to analyze the in-plane response of masonry walls. The model, accounting for the variation of the mechanical properties observed for different material directions, has been implemented in a 4-node isoparametric finite element in the FEAP code.

- A study has been performed to analyze the effect of bricks and mortar relative arrangement on the elastic properties of the homogenized material. It has emerged that different level of orthotropy can occur depending on the adopted masonry texture, thus providing useful information to identify cases in which it can not be neglected the anisotropic macroscopic characteristic of the response. 


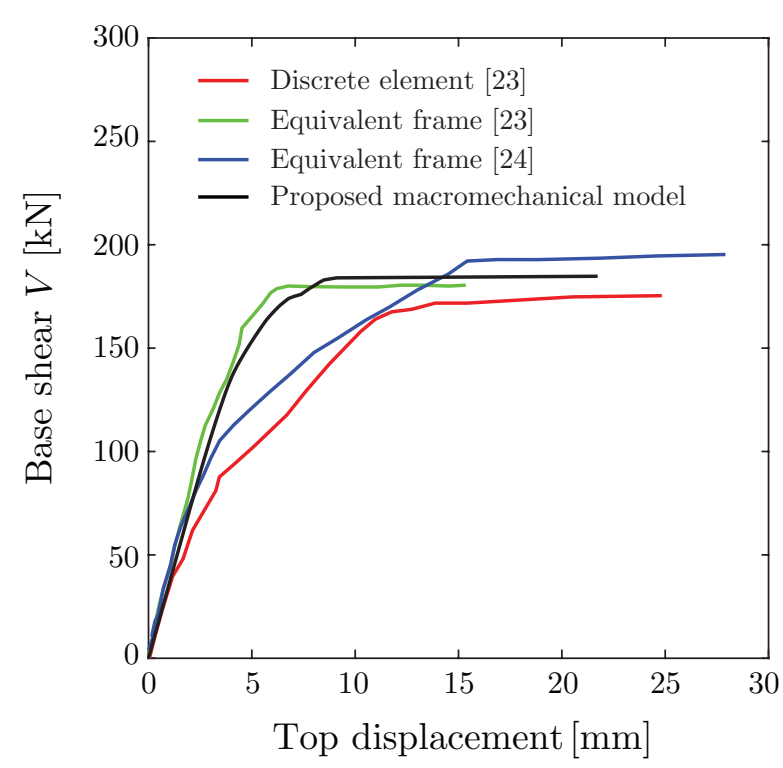

(a)

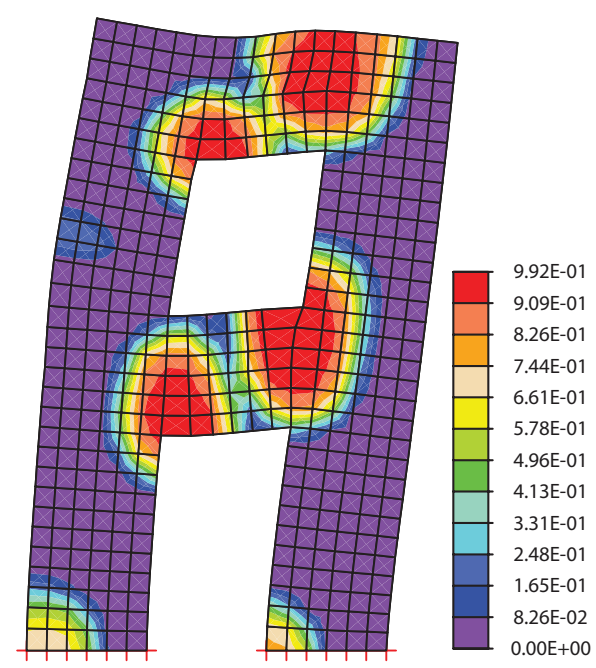

(b)

Figure 7: Two-story wall: (a) comparison between different models and the obtained load-displacement curve, (b) distribution of damage $D_{T}$ at the end of the analysis (amplified deformation).

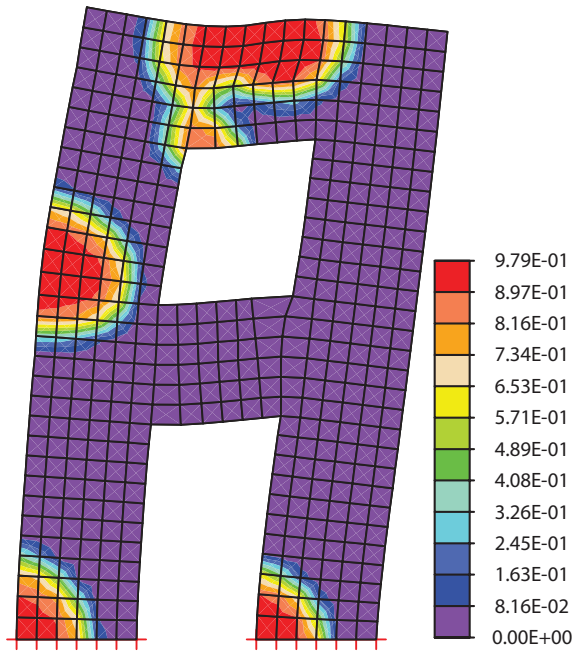

(a)

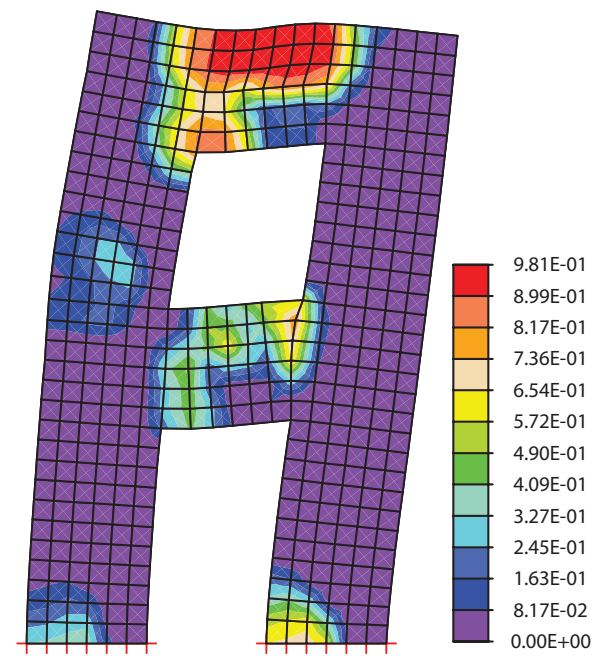

(b)

Figure 8: Two-story wall: distributions of damage (a) $D_{N}$ and (b) $D_{T N}$ at the end of the analysis (amplified deformation).

- Numerical analyses have been performed to test the capability of the proposed model of describing masonry nonlinear behavior. The comparison between numerical and experimental failure domains obtained under bi-axial stress states have highlighted the model ability in capturing influence of orientation of the applied stresses with respect to bed joints. Moreover, the seismic response of a two-story masonry wall, simulated by means of horizontal loads mimicking the first mode shape distribution, has correlated well with results obtained by existing literature models both in terms of pushover curve and damage 
distributions.

\section{ACKNOWLEDGMENTS}

This research was partially supported by: Italian Ministry of University and Research PRIN 2015, project 2015JW9NJT (Grant No. B86J16002300001, ID: 10.13039/501100003407); Sapienza Research Grants Grandi Progetti 2016 (Grant No. B82F16005920005, ID: 10.13039/ 501100004271).

\section{REFERENCES}

[1] P. Roca, M. Cervera, G. Gariup, L. Pelà, Structural analysis of masonry historical constructions. Classical and advanced approaches. Archives of Computational Methods in Engineering, 17, 299-325, 2010.

[2] T. J. Massart, R. H. Peerlings, M. G. Geers, An enhanced multiscale approach for masonry wall computations with localization of damage. International Journal for Numerical Methods in Engineering, 69, 1022-1059, 2007.

[3] D. Addessi, E. Sacco, A multi-scale enriched model for the analysis of masonry panels. International Journal of Solids and Structures, 49, 865-880, 2012.

[4] F. Greco, L. Leonetti, R. Luciano, P. Trovalusci, Multiscale failure analysis of periodic masonry structures with traditional and fiber-reinforced mortar joints. Composites Part B: Engineering, 118, 75-95, 2017.

[5] A. Zucchini, P.B. Lourenço, A micro-mechanical homogenisation model for masonry: Application to shear walls. International Journal of Solids and Structures, 46, 871-886, 2009.

[6] D. Addessi, E. Sacco, Nonlinear analysis of masonry panels using a kinematic enriched plane state formulation. International Journal of Solids and Structures, 90, 194-214, 2016.

[7] L. Leonetti, F. Greco, P. Trovalusci, R. Luciano, R. Masiani, A multiscale damage analysis of periodic composites using a couple-stress/Cauchy multidomain model: Application to masonry structures. Composites Part B: Engineering, 141, 50-59, 2018.

[8] E. Reccia, L. Leonetti, P. Trovalusci, A. Cecchi, A multiscale/multidomain model for the failure analysis of masonry walls: A validation with a combined FEM/DEM approach. International Journal for Multiscale Computational Engineering, 16, 325-343, 2018.

[9] J. Toti, V. Gattulli, E. Sacco, Nonlocal damage propagation in the dynamics of masonry elements. Computers and Structures, 152, 215-227, 2015.

[10] M. Valente, G. Milani, Non-linear dynamic and static analyses on eight historical masonry towers in the North-East of Italy. Engineering Structures, 114, 241-270, 2016.

[11] C. Gatta, D. Addessi, F. Vestroni, Static and dynamic nonlinear response of masonry walls. International Journal of Solids and Structures, 155, 291-303, 2018. 
[12] P.B. Lourenço, R. De Borst, J.G. Rots, A plane stress softening plasticity model for orthotropic materials. International Journal for Numerical Methods in Engineering, 40, 4033-4057, 1997.

[13] L. Berto, A. Saetta, R. Scotta, Renato Vitaliani, An orthotropic damage model for masonry structures. International Journal for Numerical Methods in Engineering, 55, 127-157, 2002 .

[14] L. Pelà, M. Cervera, P. Roca, An orthotropic damage model for the analysis of masonry structures. Construction and Building Materials, 41, 957-967, 2013.

[15] L. Cavaleri, M. Papia, G. Macaluso, F. Di Trapani, P. Colajanni, Definition of diagonal Poisson's ratio and elastic modulus for infill masonry walls. Materials and Structures, 47, 239-262, 2014.

[16] M. Dhanasekar, A.W. Page, P.W. Kleeman, The failure of brick masonry under biaxial stresses. Proceedings of the Institution of Civil Engineers, 79, 295-313, 1985.

[17] R.L. Taylor, FEAP-A finite element analysis program. Version 8.5. Department of Civil and Environmental Engineering, University of California at Berkeley, California. 2017.

[18] G. Pijaudier-Cabot, Z.P. Bažant, Nonlocal damage theory. Journal of Engineering Mechanics, 113, 1512-1533, 1987.

[19] A.W Page, The biaxial compressive strength of brick masonry. Proceedings of the Institution of Civil Engineers, 71, 893-906, 1981.

[20] A.W. Page, The strength of brick masonry under biaxial tension-compression. International Journal of Masonry Construction, 3, 26-31, 1983.

[21] A.W. Page, P.W. Kleeman, M. Dhanasekar, An in-plane finite element model for brick masonry. New Analysis Techniques for Structural Masonry, 1-18, 1985.

[22] D. Addessi, E. Sacco, Enriched plane state formulation for nonlinear homogenization of in-plane masonry wall. Meccanica, 51, 2891-2907, 2016.

[23] T. Salonikios, C. Karakostas, V. Lekidis, A. Anthoine, Comparative inelastic pushover analysis of masonry frames. Engineering Structures, 25, 1515-1523, 2003.

[24] A.H. Akhaveissy, Finite element nonlinear analysis of high-rise unreinforced masonry building. Latin American Journal of Solids and Structures, 9, 1-22, 2012.

[25] E. Sacco, A nonlinear homogenization procedure for periodic masonry. European Journal of Mechanics-A/Solids, 28, 209-222, 2009. 